Thesis Summary

\title{
SOME EFFECTS OF WIND ON THE GROWTH OF WHITE CLOVER (TRIFOLIUM REPENS L.) SEEDLINGS
}

\author{
J. S. BIRCHAM \\ A gronomy Department, Massey University
}

THE EFFECTS of wind velocity on Trifolium repens L. cv. 'Grasslands Huia' white clover seedlings were examined in a wind tunnel. Three experiments were conducted, each at a different wind velocity, in which wind was applied to seedlings at three distinct stages of growth (cotyledons, unifoliate leaf and trifoliate lcaf) for three periods of time (two, four and six days). The wind velocities were $5.0,7.5$ and $10.0 \mathrm{~m} / \mathrm{s}$. In all experiments total plant, shoot and root dry weights and shoot/root ratios were determined after 28 days.

All three wind velocities had a marked effect on total plant, shoot and root dry weights and root/shoot ratios. Relative growth rates during the application of wind were generally higher at $5.0 \mathrm{~m} / \mathrm{s}$ than at $10.0 \mathrm{~m} / \mathrm{s}$. They were also higher at the unifoliate stage of growth than at either the cotyledon or trifoliate stages of growth during wind application. After the application of wind, the trends of response were reversed. Wind duration generally had little effect. In one experiment where net assimilation rates were measured, the pattern of response both during and after the application of wind was similar to that of the relative growth rates. The relative water content determinations indicated the existence of water stress which was alleviated when the wind ceased. Wind generally had no effect on the rate of transpiration but closed the stomata of the most prominent leaves. The relevance of the results to the field situation is discussed. 